УДК 82.091

DOI: $10.17223 / 24099554 / 4 / 5$

\title{
Е.В. Аблогина
}

\section{НЕМЕЦКИЕ VERNUNFT, VERSTAND И РУССКИЙ УМ: ПЕРЕВОД «ПРОЛОГА В ТЕАТРЕ» И.В. ГЕТЕ КАК «ЦЕНТРАЛЬНОЕ ЭСТЕТИЧЕСКОЕ ВЫСКАЗЫВАНИЕ ГРИБОЕДОВА»}

Вольный и неполный перевод «Пролога в театре» из первой части трагедии «Фауст» приобрел новое кониептуальное звучание и практическую автономность от сюжета И.В. Гете, став выражением собственного драматургического кредо Грибоедова. В контексте творчества Грибоедова, который осуществлял переводы-переделки преимущественно с франиузского, Гете представительствует от лица немеикой культуры, которая посредством перевода оказывается вовлечена в концептуальное поле комедии «Горя от ума».

Ключевые слова: А.С. Грибоедов, И.В. Гете, «Пролог в театре», перевод, рецеепциия, ум.

Зрелое творчество Грибоедова охватывает период меньше десятилетия: с начала 1820 г. по 30 января 1829 г., когда его жизнь трагически оборвалась в Тегеране. За это время были написаны самая известная комедия Грибоедова «Горе от ума» (18221824 гг.), опера-водевиль в одном действии «Кто брат, кто сестра, или Обман за обманом» (1823-1824 гг.), несколько стихотворений, эпиграмм и статей, десятки писем, многие из которых потом назовут шедеврами эпистолярной прозы, переведен «Пролог в театре» (другое название - «Отрывок из Гете», 1824-1825 гг.). Большинство драматических произведений этого периода сохранились лишь в набросках. Среди них «Юность Вещего» - фрагменты плана пролога исторической пьесы о Ломоносове (около 1824 г.), отрывок из неоконченной драмы о борьбе русских с половцами «Серчак и Итляр» (1825 г.), план трагедии «Родамист и Зенобия» (предположительно 1822-1828 гг.), отрывок и план драмы «1812 год» (1822-1828 гг.), трагедия «Грузинская ночь» (1826-1827 гг.).

В 1824-1825 гг. Грибоедов продолжает напряжено работать над завершением и отделкой комедии «Горе от ума», параллельно обдумывая планы новых произведений: драматического пролога о юности Ломоносова, трагедии на темы средневековой русской ис- 
тории, в соавторстве с П.А. Вяземским начинает сочинять оперуводевиль «Кто брат, кто сестра, или Обман за обманом», также пишет стихотворения, очерки. В это время переводы уже не играют такой роли, как в период ученичества, когда он переводилпеределывал для театра французских авторов второго ряда. Теперь Грибоедов переводит лишь тех авторов, которые представляют для него интерес и высоко им ценятся. Так, А.А. Бестужев в воспоминаниях приводит слова Грибоедова, сравнивавшего И.В. Гете с Байроном: «Между ними всё превосходство должно отдать Гете: он объясняет своею идеею все человечество <...> едва ли творения Шекспира выдержат сравнение с гетевскими» [1. С. 99].

Близкий друг Грибоедова С.Н. Бегичев также указывал, что Грибоедов знал Гете почти наизусть [1. С. 26] $]^{1}$. На этом фоне обращение к «Фаусту» выглядит отнюдь не случайным.

Примечательно, что в это время Гете еще был мало известен русскому читателю. Переводы его лирики и сведения о нем, которые появляются на страницах русских журналов 1820-х гг., немногочисленны и случайны. По словам В.М. Жирмунского, В.А. Жуковский, переводя лирику Гете в 1816-1818 гг., исходил из целостного, хотя и односторонне-субъективного восприятия его творчества, а большинство поэтов 1810-1820-х гг. (А.А. Дельвиг, А. Мещевский, А. Глебов, А. Бистром, П. Ободовский и мн. др.) ограничивались формальным усвоением и использованием тех или иных аспектов его лирики, перекликающихся с их собственными творческими установками [3. С. 72-86]. Таким образом, Грибоедов, обратившийся в 1824 г. к «Фаусту», выступил одним из первых переводчиков драматургии Гете.

Характерно, что внимание Грибоедова привлек не один из философско-лирических монологов Фауста, которые вскоре станут известны в переводах романтиков «немецкой» школы Д.М. Веневитинова, Ф.И. Тютчева и др., а «Пролог в театре» - творческий манифест, связанный именно с драмой. Думается, выбор «Пролога в театре» не был обусловлен интересом Грибоедова к сатире на театральную публику, заключенную в репликах Директора, как полагал В.Л. Жирмунский [3. С. 79-80], потому в своем переводе Грибоедов отбросил четыре заключительные реплики «Пролога», завершив свой вариант монологом Поэта, восхваляющим богорав-

${ }^{1}$ С.М. Козлова также усматривает в отдельных заметках и письмах Грибоедова очевидную близость с поэтикой «Западно-восточного дивана» [2. С. 123]. 
ное величие творческой личности. Тем самым перевод приобрел совершенно иное концептуальное звучание и практическую автономность от сюжета «Фауста», став выражением собственного драматургического кредо Грибоедова.

В.М. Жирмунский отмечал, что Грибоедов «широко развертывает сатирическое обозрение Директора, превращая его в сатиру на современное общество, каким оно является в театральных креслах, переосмысленную в духе обличительных монологов Чацкого» [3. С. 79-80]. Действительно, переводя спор персонажей «Пролога»Директора, Комического актера (Весельчака) и Поэта - о театре и толпе, Грибоедов стремится вложить в их диспут собственное понимание целей искусства и роли поэта, во многом продиктованное современной ему действительностью. Намеки на николаевскую цензуру, не пропускавшую в печать и на сцену новаторские пьесы Грибоедова и его товарищей:

<...> Здесь озираются во мраке подлецы,

Чтоб слово подстеречь и погубить доносом <...> [4. Т. 2. С. 228],

ирония по отношению к тем, кто уступает цензуре и печатается в известных журналах:

$<\ldots>$ Иной небрежный ловит стих -

Сотрудник глупых он журналов [4. Т. 2. С. 228],

презрительное отношение к театральной публике, которая без разбору «валит» в театр, «как будто их рождает преисподня» [4. Т. 2. С. 226] все это привнесено в «Пролог» Грибоедовым.

Примечательно, что при переводе Грибоедов соблюдает кольцевую рифмовку стиха Гете, но перекрестную чаще заменяет на парную, что делает речь Директора более естественной для русского читателя, приближает по звучанию к разговорной - такой способ рифмовки широко используется им и в «Горе от ума».

В целом перевод Грибоедова довольно близок к оригиналу, тем не менее в нем есть симптоматичные модификации, связанные с мотивом ума, который возникает независимо от наличия соответствий в тексте Гете. Так, Грибоедов вводит мотив ума в реплики Директора. 
Cp.:

Гете

Ich wünschte sehr der Menge zu behagen,

Besonders weil sie lebt und leben läßt.

Die Pfosten sind, die Bretter aufgeschlagen,

Und jedermann erwartet sich ein Fest [5. S. 10].

- Я бы хотел толпе нравиться, Особенно потому, что она живет и позволяет жить.

Столбы и доски сколочены, И каждый ждет праздника ${ }^{1}$.

Wir machen wir's, daß alles frisch und neu

Und mit Bedeutung auch gefällig sei [5. S. 6].

Грибоедов

Чтоб большинство людей осталось мной довольно,

Которое живет и жить дает. Дом зрелища устроен пребогатый, И бревяной накат, и пол дощатый, И все по зву: один свисток Храм взыдет до небес, раскинется лесок.

Лишь то беда: ума нам где добиться?

[4. T. 2. C. 226]

Чтоб были вещи им новы, И складно для $у м а$, и для души отрадно

[4. T. 2. C. 226]

- Мы делаем все так, чтобы было свежо и ново,

И смысл тоже привлекал.

Директор у Грибоедова говорит о том, что в публике много знатоков, и, чтобы угодить им, нужно приспособиться к их запросам; ум в данном случае - прагматический расчет, рассудочность, которая необходима Поэту, дабы угодить публике. Потому Директор, убеждая Поэта, заключает:

Что? гордости порыв утих? Рассудок превозмог... [4. Т. 2. С. 228].

Грибоедов по-своему видит и спор участников «Пролога» о театре. Позиция Директора у Гете достаточно проста: он жаждет успеха, стремится привлечь постановкой как можно больше зрителей, его очень радует толпа перед театром. Он сторонник прагматического подхода, ничего творческого в этом ремесле он не видит. Театр для него лишь средство развеять скучающую толпу. В своем переводе Грибоедов добавляет Директору явно выраженное ироническое отношение к толпе. Он замечает, что публика ждет и требует чего-нибудь нового, «складного для ума» и «для души отрадного», так как о многих драматургических произведениях уже знает, хотя и понаслышке:

\footnotetext{
${ }^{1}$ Здесь и далее подстрочный пер. с нем. наш. - E.A.
} 
Не то, чтобы у нас к хорошему привыкли, Да начитались столько книг! [4. Т. 2. С. 226].

Зрители склонны долго рассуждать о театре, но опять же лишь от скуки. По мнению грибоедовского Директора, толпа глупа и неразборчива, она жаждет лишь развлечений, а подлинное искусство и высокие идеи ей неинтересны. Оппонентом Директора в споре выступает Поэт, изображенный Гете в романтических тонах. По контрасту с Директором Поэт говорит возвышенно и высокопарно, толпу он ассоциирует с затягивающей трясиной, суетой, пошлостью, в то время как творцу нужны покой, уединение. Для Поэта театр представляет прежде всего высокое искусство. У Грибоедова образ Поэтаромантика иронически заострен. Он критично относится к толпе: толпа, по его словам, клюет на блеск, который изменчив, в то время как искусство вечно. Промежуточную позицию между Директором и Поэтом у Гете занимает Комический актер (Весельчак). Он высказывает примирительную мысль: любому талантливому актеру толпа необходима: восхищение, восторг толпы должны его вдохновлять. Грибоедов точно передает эту реплику, но опускает фразу, вводящую тему ума у Гете. И в этом снова видна ирония: актер, желающий славы, признания, должен лишь удовлетворять нехитрым запросам публики - ум при этом не нужен.

Спор о театре, поэте и толпе Грибоедов прерывает на последней реплике Поэта, суть которой в том, что поэт не должен писать в угоду толпе. В поэте, по его мнению, сосредоточены божественная сила, творческое начало, и рассудочность, которую Директор понимает под умом, абсолютна неприемлема:

Ты постигаешь ли умом

Создавшего миры и лета? [4. Т. 2. С. 229].

Очевидно, позиция Поэта близка самому Грибоедову, который

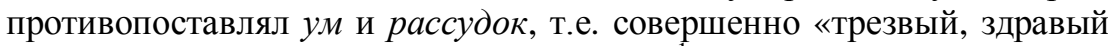
ум», отдавая явное предпочтение первому. Это в большей мере видно на материале комедии «Горе от ума» и также может быть соотне-

${ }^{1}$ Ср. Грибоедов в письме С.Н. Бегичеву: «Я такой же, какой был и прежде, пасынок здравого рассудка» [4. Т. 3. С. 11]. Вероятно, в трактовке здравомыслия Грибоедову были близки размышления К.А. Гельвеция, утверждавшего в трактате об уме, что «не нужно иметь ни большого скудоумия, ни большой широты ума, чтобы казаться здравомыслящим, ибо здравым смыслом почти все называют согласие с тем, что признается глупцами, а человек, который ищет лишь истину и поэтому обычно отклоняется от принятых истин, считается сумасшедшим» [6. С. 580]. 
сено с высказыванием И.Н. Розанова, который комментировал использование Грибоедовым эпитета умный следующим образом: «<...> если же он (Грибоедов. - E.A.) употребляет выражение “трезвый ум”, то это у него звучит обыкновенно синонимом пошлости» [7. С. 119-120].

Промежуточную позицию между Директором и Поэтом у Гете занимает Комический актер (Весельчак), который призывает Поэта творить не во имя абстрактных идеалов, самовыражения или во благо потомков, но живо и динамично писать для современной публики. Грибоедов отвергает и эту позицию, предполагающую $y_{м}$ как рассудочное начало в творчестве, потому в реплике Весельчака Грибоедов не передает имеющиеся у Гете die Vernunft - «разум, рассудок» и der Verstand - «ум, рассудок». Ср.:

Гете

Laßt Phantasie mit allen ihren Chören, Vernunft, Verstand,

Empfindung, Leidenschaft,

Doch, merkt euch wohl! nicht ohne

Narrheit

hören! [5. S. 11].

- Дайте услышать фантазию со всеми ее хорами,

Разумом, умом,

Чувством, страстью,

Но, запомните хорошенько!

не без дурачества!
Грибоедов

Скорей Фантазию, глас скорби безотрадной,

Движенье, пыл страстей, весь хор ее нарядный

К себе зовите на чердак,

Дурачеству оставьте дверцу,

Не настежь, вполовину, так,

Чтоб всякому пришло по сердцу

[4. T. 2. C. 227].

Можно также предположить, что Грибоедов, переводя «Пролог» Гете, вступает в диалог с А.С. Пушкиным, который в 1824 г. написал «Разговор книгопродавца с поэтом» и годом позже опубликовал его как вступление к первой части «Евгения Онегина». Стихотворение Пушкина также представляло собой столкновение представлений о целях поэтического искусства, его назначении ${ }^{1}$. Поэт у Пушкина высказывал мысль, что поэзия самоценна, она не должна ориентироваться на толпу, тем более действовать ей в угоду:

$<. .>$ Делиться не был я готов

С толпою пламенным восторгом,

И музы сладостных даров

Не унижал постыдным торгом [9. С. 291].

${ }^{1}$ О связи между «Отрывком из Гете» и «Разговором книгопродавца с поэтом» см.: [8. C. 101-106]. 
Книготорговец, напротив, придерживается мнения, что труд поэта должен приносить ему славу и деньги:

<...> Не продается вдохновенье,

Но можно рукопись продать [9. С. 294].

Так необходимость заставляет пушкинского Поэта продать рукопись Книготорговцу.

Очевидно, что позиции Грибоедова и Пушкина схожи: оба понимают, что искусство творится высокой поэтической личностью, оно высоко по своему устремлению, противоположному толпе, но при этом вынуждено считаться с реальностью, т.е. с той толпой, которая дает средства для существования поэта. Оба ставят сложнейший вопрос деонтологии творчества - вопрос о свободе творческой личности - и решают его в направлении определенного компромисса. А.А. Дубровин по этому поводу отмечает:

Из его (Грибоедова. - Е.А.) слов следует, что, рассматривая зрительскую толпу как невежественную и неспособную воспринять высшую поэзию, театральное искусство не должно тем не менее нисходить до простой забавы, стремясь к угождению неразвитым вкусам. Драматический поэт не должен забывать, что его пьеса - зрелище, и обязан приложить все свое искусство, чтобы понравиться зрителям, но при этом заботиться о правдоподобии так, как будто зрителя не существует [10. С. 33].

То, что Грибоедов завершает перевод словами Поэта, придает позиции этого персонажа особую весомость: если Гете обобщает, синтезирует все три точки зрения, то Грибоедов отдает предпочтение позиции Поэта. На этом основании Л.А. Степанов заключает, что Грибоедов «был свободен от особого противоречия, жившего в душе Гете, противоречия между позициями директора театра и автора. Он целиком принимает позицию Поэта и выражает ее с еще большей эмоциональностью и глубиной» [11]. Думается, позиция Грибоедова несколько сложнее, отношение к доводам оппонентов Поэта не столь однозначно. К такому выводу приходит М.А. Александрова: «...внутренний конфликт автора воплощается в “Отрывке из Гете" несколько иначе, нежели в первоисточнике: вместо диалогического столкновения разных позиций - почти независимое, хотя и не вполне равноправное звучание голосов. Замкнутое монологическое сознание в итоге торжествует, за Поэтом-мессией остается последнее слово. Однако это “торжество” объективно корректируется самоочевидной правотой 
других персонажей» [12. С. 117]. Такая оценка перевода из Гете сообразна наблюдению В.М. Марковича, отмечавшего принцип компромисса, синтеза, свойственный эстетике Грибоедова: «...принцип компромисса пронизывает <...> весь художественный строй “Горя от ума" <...> Компромисс превращается в плодотворный синтез традиций и новаторства» [13. С. 75].

Осуществляя перевод отрывка из «Фауста», Грибоедов делает «Пролог в театре» своеобразным манифестом своей драматургии Л.А. Степанов справедливо называет перевод из Гете «центральным и наиболее полным эстетическим высказыванием Грибоедова» [11. C. 10].

Поэтому данный перевод Грибоедова представляет интерес не столько как пример обращения русского автора к произведению Гете, сколько в плане осмысления зрелого творчества Грибоедова.

\section{Лuтература}

1. А.С. Грибоедов в воспоминаниях современников / отв. ред. В.Э. Вацуро. М., $1980.447 \mathrm{c}$.

2. Козлова С.М. Миростроительная функция сна и сновидения в комедии «Горе от ума» // А.С. Грибоедов. Хмелитский сб. Смоленск, 1998. С. 123.

3. Жирмунский В.М. Гете в русской литературе: избранные труды. Л., 1982. 558 с.

4. Грибоедов. А.С. Полное собрание сочинений: в 3 т. / подгот. текста и коммент. А.Л. Гришунина; науч. ред. С.А. Фомичев. СПб., 1995-2006. Т. 1-3.

5. Goethe I.W. Werke: in 14 Bänden. München, 1993. Bd. 3. 775 s.

6. Гельвеций К.-А. Сочинения: в 2 т. М., 1973. Т. 2. 687 с.

7. Розанов И.Н. Грибоедов и Пушкин // Пушкинский сборник. М., 1900. 302 с.

8. Фесенко Ю.П. Пушкин и Грибоедов // Временник Пушкинской комиссии. 1980. Л., 1983. С. 101-106.

9. Пушкин А.С. Полное собрание сочинений: в 17 т. / под ред. В.Д. БончБруевича. М., 1994. Т. 2, кн. 1. 511 с.

10. Дубровин А.А. А.С. Грибоедов и художественная культура (литературоведческий и фольклористический аспекты) : автореф. дис. ... д-ра филол. наук. М., 1995. 39 с.

11. Степанов Л.А. О стихотворении А.С. Грибоедова «Отрывок из Гете»// Филология-Philologica. Краснодар, 1995. № 5. С. 10-13.

12. Александрова М.А. Комедиография А.С. Грибоедова: Творческая эволюция : дис. ... канд. филол. наук. Н. Новгород, 2000. 215 с.

13. Маркович В.М. Комедия в стихах А.С. Грибоедова «Горе от ума» // Анализ драматического произведения : межвуз. сб. Л., 1988. С. 59-91.

GERMAN VERNUNFT, VERSTAND AND RUSSIAN UM: ALEKSANDR GRIBOEDOV'S LOOSE TRANSLATION OF GOETHE'S “VORSPIEL AUF DEM THEATER” AS “GRIBOEDOV'S CENTRAL AESTHETIC STATEMENT”

Imagology and Comparative Studies, 2015, 2(4), pp. 111-120. DOI: 10.17223/24099554/4/5 
Ablogina Evgeniia V. Tomsk State University (Tomsk, Russian Federation). E-mail: e.ablogina@gmail.com

Keywords: Aleksandr Griboedov, J.W. Goethe, Vorspiel auf dem Theater, translation, reception, um.

Besides the famous comedy Gore ot uma, Aleksandr Griboedov's mature works (early 1820 - January 30, 1829) include an opera-vaudeville, numerous drama drafts, some poems, epigrams and articles, dozens of letters and a fragment translation from Goethe's Faust dating back to Gore ot uma period of 1822-1824. Though Griboedov translated primarily from French comedians, by translating Goethe he addressed German culture to involve it in the conceptual field of Gore ot uma. Griboedov paid attention to Goethe's Faust even before it was translated into Russian, which was obviously due to his personal interest. He highly appreciated Goethe, as is evident from his close friends' memoirs.

As Griboedov's translation from Faust was loose and incomplete, it acquired a new conceptual meaning and independence from the original plot to become his drama statement. The plot of the translated fragment is rather close to the original, yet it contains specific modifications connected with the motif of $u m$, with the latter appearing regardless of Goethe's text. Griboedov interprets the central debate of Vorspiel's characters about theatre in his own way. In the Russian translation the Director sees theater viewers as an indiscriminate and silly crowd that craves for entertainment, rather than high ideas. The Director is opposed by the Poet described by Goethe in a romantic way. Griboedov, however, makes the Poet sound ironical: the Poet is critical of the theatre crowd attracted by fickle splendour, while art is eternal. Griboedov ends the whole debate about theatre, poet and crowd with the the Poet's last cue that no poet must write in order to please the crowd. In his opinion, the poet accumulates the divine power and creativity, so um as rationality, as it is understood by the Director, is unacceptable.

It can also be assumed that in his translation of Goethe's Prologue Griboedov enters into a dialogue with Aleksandr Pushkin's The Conversation of the Bookseller with the Poet (1824) published as an introduction to the first chapter of Eugene Onegin. Both Pushkin and Griboedov set a complex question related to deontology of creation: Is a creative personality free or not? In both cases the answer leads to a compromise. Hence, the translated fragment from Goethe's Faust becomes Griboedov's original statement about dramatic art, which makes this translation interesting for understanding mature Griboedov's writing, rather than in its relation to Goethe's tragedy.

\section{References}

1. Vatsuro, V. E. (1980) A.S. Griboedov v vospominaniyakh sovremennikov [A.S. Griboyedov in the Memoirs of His Contemporaries]. Moscow: Khudozhestvennaya literatura.

2. Kozlova, S.M. (1998) Mirostroitel'naya funktsiya sna i snovideniya v komedii "Gore ot uma" [The world-making function of sleep and dreams in the comedy Woe From Wit]. In: Kulakov, V., Koshelev, V., Merkin, G. \& Fomichev, S. (eds) A.S. Griboedov. Khmelitskiy sbornik [A.S. Griboyedov. The Khmelitsky Collection]. Smolensk: Smolensk University for the Humanities. p. 123.

3. Zhirmunskiy, V.M. (1982) Gete v russkoy literature: Izbrannye trudy [Goethe in Russian Literature: Selected Works]. Leningrad: Nauka.

4. Griboedov, A.S. (1995-2006) Polnoe sobraniye sochineniy: $v 3 t$. [Complete Works. In 3 vols.]. St. Petersburg. 
5. Goethe, I.W. (1993) Werke: in 14 Bänden [Works. In 14 vols.]. Translated from German. Vol. 3. Munich.

6. Helvetius. (1973) Sochienia: V 2 t. [Works. In 2 vols.]. Vol. 2. Moscow.

7. Rozanov, I.N. (1900) Griboedov i Pushkin [Griboedov and Pushkin]. In: Kirpichnikov, A.I. (ed.) Pushkinskiy sbornik [The Pushkin Collection]. Moscow: University Typography.

8. Fesenko, Yu.P. (1980) Pushkin i Griboedov [Griboedov and Pushkin]. In: Alekseev, M.P. \& Fomichev, S.A. (eds) Vremennik Pushkinskoy komissii [The Annals of the Pushkin Commission]. Leningrad: USSR Academy of Sciences. pp. 101-106.

9. Pushkin, A.S. (1994) Polnoe sobraniye sochieniy: $v 17$ t. [Complete Works. In 17 vols.]. Vol. 2. Moscow.

10. Dubrovin, A.A. (1995) A.S. Griboedov i khudozhestvennaya kul'tura (literaturovedcheskiy i fol'kloristicheskiy aspekty) [A.S. Griboedov and artistic culture (the folklore and literary aspects)]. Abstract of Philology Doc. Diss. Moscow.

11. Stepanov, L.A. (1995) O stikhotvorenii A.S. Griboedova "Otryvok iz Gete" [On A.S. Griboyedov's poem "A Fragment from Goethe]. Filologiya-Philologica. 5. pp. 10-13.

12. Aleksandrova, M.A. (2000) Komediografiya A.S. Griboedova. Tvorcheskaya evolyutsiya [A.S. Griboyedov's comedies. Creative Evolution]. Philology Cand. Diss. Nizhny Novgorod.

13. Markovich, V.M. (1988) Komediya v stikhakh A.S. Griboedova "Gore ot uma" [A.S. Griboyedov's verse comedy Woe From Wit]. In: Markovich, V.M. (ed.) Analiz dramaticheskogo proizvedeniya [The Drama Analysis]. Leningrad: Leningrad State University. pp. 59-91. 